\title{
Plasma Stress Responses in Juvenile Red-Spotted Grouper (Epinephelus akaara) exposed to Abrupt Salinity Decrease
}

\author{
Jang-Won Lee ${ }^{1}$, Hyung Bae Kim ${ }^{2}$ and ${ }^{\dagger}$ Hea Ja Baek ${ }^{1}$ \\ ${ }^{1}$ Dept. of Marine Biology, Pukyong National University, Busan 48513, Korea \\ ${ }^{2}$ Dept. of Marine Bio-resources, Gangwon Provincial College, Gangnung 25425, Korea
}

\begin{abstract}
The objective of the current study was to determine acute plasma stress responses in two size groups of juvenile Epinephelus akaara (average body weight: $8.4 \pm 2.1$ and $3.3 \pm 0.6 \mathrm{~g} ; 150$ and 120 days after hatch, respectively) exposed to abrupt salinity drops (from 34 practical salinity unit, PSU seawater to 18, 10 PSU (experiment 1) or 26, 18, 10 PSU (experiment 2), respectively). Plasma glucose, glutamic oxalate transaminase, glutamic pyruvate transaminase, red blood cell counts, and gill histology were determined during $72 \mathrm{~h}$ exposure. Significantly increased plasma glucose, glutamic oxalate transaminase levels, and red blood cell counts were observed in fish exposed to 18 or 10 PSU. Histological changes, such as hyperplasia and lifting of epithelium in the gill secondary lamellae, were also observed in fish exposed to 18 or 10 PSU at 72 h post-drop. E. akaara exposed to sudden salinity drops to 18 or 10 PSU still seems to undergo the primary adjustment phase before fish reaches a new homeostasis, whereas fish exposed to 26 PSU seems to mount osmotic changes. Therefore, the no observed adverse effect levels for $72 \mathrm{~h}$ acute salinity challenge was 26 PSU in our study, and salinity drop to 18 PSU and below can possibly cause acute adverse effect, in which fish could be vulnerable to additional stresses such as a temperature changes or handling stress.
\end{abstract}

Key words : Red spotted grouper, Epinephelus akaara, Salinity decrease, Plasma stress response, Gill histology

\section{INTRODUCTION}

Red-spotted grouper (Epinephelus akaara) that belong to subfamily Epinephelinae of the family Serranidae is a tropical marine species in Southeast Asia (Randall, 1987). E. akaara has been heavily targeted in fisheries because of high market prices (Randall, 1987; Morris et al., 2000). Since 2003, red-spotted grouper has been listed as an endangered species on the International Union for the Conservation of Nature (IUCN) red list of threatened species (Cornish, 2003). In the natural habitat of E. akaara, rainy season (monsoon) brings heavy precipitation and subsequent freshwater influx into coastal seawater, being leading to dramatic salinity decrease (below 20 ppt) (Lü et al., 2015). Juvenile E. akaara occur in relatively shallow coastal water in comparison to large adult individuals (Cornish, 2003), and thus juveniles are likely to encounter salinity changes as a result of precipitation. While interest in developing E. akaara aquaculture has been increasing (Cho et al., 2015; Park et al., 2016), there is paucity of published information on environmental physiology of the species such as salinity tolerance and preference.

\footnotetext{
Manuscript received July 01, 2016, Received in revised form July 20, 2016, Accepted September 05, 2016

${ }^{\dagger}$ Corresponding Author: Hea Ja Baek, Dept. of Marine Biology, Pukyong National University, Busan 48513, Korea. Tel. : +82-51-629-5924, Fax : +8251-629-5931, E-mail : hjbaek@pknu.ac.kr

This is an Open Access article distributed under the terms of the Creative Commons Attribution Non-Commercial License (http:// creativecommons.org/licenses/by-nc/3.0) which permits unrestricted non-commercial use, distribution, and reproduction in any medium, provided the original work is properly cited.
} 
Changes in environmental salinity as a stressor can cause physiological and morphological adjustments in osmoregulatory system of fish (Sangiao-Alvarellos et al, 2005; Arjona et al., 2007). This osmoregulation is an energy demanding process that requires mobilization of energy substrates from the body (Vargas-Chacoff et al., 2009; Shahkar et al., 2015). The mobilization is triggered by plasma cortisol and/or catecholamine levels, which lead to elevation in blood glucose levels (Mommsen et al., 1999; Moyle \& Cech, 2004). Thus, plasma glucose level provides useful information about the fish's physiological status under salinity stress (Mommsen et al., 1999; Laiz-Carrion et al., 2002). Some of soluble enzymes in blood plasma have been considered as indicators of hepatic dysfunction and damage (Asztalos et al., 1990; Datta et al., 2007). Glutamic oxalate transaminase (GOT) and glutamic pyruvate transaminase (GPT) are dominant in cardiomyocytes and hepatocytes, respectively (Bhattacharya et al., 2008). When liver and myocardiocytes are damaged or their permeability increased, GOT and GPT are released into the blood (Wang et al., 2005; Gholami-Seyedkolaei et al., 2013). Thus, blood GOT and GPT can be used to detect tissue damage in fish (Wang et al., 2005). Hematological changes including red blood cell (RBC) volume and plasma osmolality can be accompanied by environmental changes such as salinity changes depending on severity of changes and species (Moyle \& Cech, 2004). Hematological change caused by salinity change is usually a physiological adaptation mechanism to overcome osmotic disturbance and reach a new homeostasis in fish (Jensen et al., 2002).

The ability to tolerate various salinity ranges differs with species (Kindle \& Whitmore, 1986; Arjona et al., 2007) and also with body mass. Yet, none has determined what levels of salinity decrease and subsequent changes in physiological parameters can lead to morphological changes in tissue levels in E. akaara. To identify effects of stressors, histological examinations of fish tissues have proven to be a reliable tool in controlled experiments and field studies
(Teh et al., 1997; Lee et al., 2012). Especially, examination of gills histology is meaningful because gills are a primary osmoregulatory organ and its morphological changes can affect gas exchange of whole animal as well as osmoregulatory capacity.

Stress and unfavorable environmental conditions can compromise normal development and growth (Akatsu et al., 1983; Arjona et al., 2009). Thus, finding optimal environmental condition including salinity is a key to establishment of sustainable aquaculture. A group of researchers reported a significantly higher survival and growth of larval brown-spotted grouper, Epinephelus tauvina, at a salinity of 25 PSU (Akatsu et al., 1983). Also, it is a widely accepted practice that when fish is transported, lowering salinity of transportation medium than salinity in grow-up tanks. Aquaculture farms in the South China are located in the coastal area, which encounter sudden salinity drops (below $20 \mathrm{ppt}$ ) as a result of rain (Lü et al., 2015). It is critical to know physiological responses of E. akaara to salinity decreases in juvenile stage. To our knowledge, it is the first study to look at plasma and histological stress responses in juvenile E. akaara exposed to salinity de-creases. The objective of the current study was to investigate acute plasma stress responses and gill histological changes in two size groups of juvenile E. akaara exposed to abrupt salinity drops (from 34 PSU to 18,10 or 26, 18, 10 PSU, respectively) to determine salinity tolerance range(s).

\section{MATERIALS AND METHODS}

\section{Acquisition of juvenile Epinephelus akaara and preliminary acclimation}

For experiment 1, E. akaara was hatched and raised at the Marine Science Research Institute, Jeju National University, Jeju, Korea at a controlled environmental condition (temperature: $23 \pm 0.5^{\circ} \mathrm{C}$, salinity: $34 \pm 0.5$ practical salinity unit, PSU, dissolved oxygen, DO: $8.5 \pm 0.5 \mathrm{mg} / \mathrm{L}, \mathrm{pH}: 7.8 \pm 0.4$ ) 
before transportation. Five-month old fish (150 days after hatch, DAH) of similar size were selected and transported from the Marine Science Research Institute to the laboratory at Pukyong National University, Busan, Korea. The transported fish were gradually acclimated at the environmental conditions $\left(20 \pm 1^{\circ} \mathrm{C}, 34 \pm 1\right.$ PSU, DO: $\left.\geq 7.4 \mathrm{mg} / \mathrm{mL}, \mathrm{pH}: 7.5 \pm 0.3\right)$ for 2 weeks prior to the salinity experiment. During the 2week acclimation period, the E. akaara were fed a commercial feed (Aquapro Flounder, Le Gouessant, France) to ad libitum twice a day. For experiment 2, E. akaara were hatched and raised at Fish Farm, Muangun, Korea at a controlled indoor environments (temperature: $25 \pm 1.5^{\circ} \mathrm{C}$, salinity: $33 \pm 2$ PSU, DO: $7.0 \pm 0.5 \mathrm{mg} / \mathrm{L}, \mathrm{pH}: 7.4 \pm 0.5$ ) before transportation. After four-month old E. akaara (120 DAH) were selected and transported from the farm to the laboratory at Pukyong National University. Then, the transported fish were gradually acclimated and maintained in a very similar manner as for the experiment 1 for 2 weeks before the salinity experiment.

\section{Experimental design}

For experiment 1, a total of 20 E. akaara of similar size (150 DAH, mean total length: $8.1 \pm 0.22 \mathrm{~cm}$; body weight: $8.4 \pm 2.1 \mathrm{~g}$ ) was selected and randomly distributed to three 120-liter rectangular glass tanks (recirculating water systems, $75 \times 43 \times 43 \mathrm{~cm}$ ) with temperature controllers (OKE-6422H, OKE, Korea) and biological filtration (5 fish/tank). Then, one of the three different experimental salinities $(34,18$, 10 PSU) was randomly assigned to each of three tanks. For experi-ment 2, a total of 80 E. akaara of similar size (120 DAH, mean total length: $6.2 \pm 0.6 \mathrm{~cm}$; body weight: $3.3 \pm 0.6$ g) were selected and randomly distributed to four tanks (20 fish/tank), and then one of the four different experimental salinities (34, 26, 18, 10 PSU) was randomly assigned to each of four tanks. Different salinities were provided by mixing filtered seawater with dechlorinated filtered tap water in advance. Temperature, dissolved oxygen, $\mathrm{pH}$, and salinity were checked and adjusted daily using a portable water quality meter (HI9829, Hanna Instrumentals, Woonsocket, RI, USA) and maintained at $20 \pm 1^{\circ} \mathrm{C}$, dissolved oxygen: $\geq 7.1 \mathrm{mg} / \mathrm{L}, \mathrm{pH}: 7.80 \pm 0.2$ respectively. Ammonia levels were regularly checked using $\mathrm{NH}_{3} / \mathrm{NH}_{4}{ }^{+}$test kit (Tetra GmbH, Melle, Germany) and were maintained at undetectable levels. Both experiments were separately conducted for 72 $h$, because the second experiment was conducted with additional sampling time points, salinity (26 PSU), and a different size group to confirm and supplement the first experiment. Fish were fasted during the trials. Any debris and feces was siphoned out daily for additional water quality control and fresh seawater was refilled (about 10\% water change/day). All experimental procedures were conducted according to the guidelines of Animal Ethics Committee Regulation, No. 554 established by Pukyong National University, Busan, Korea.

\section{Fish sampling and biochemical analysis}

Fish were fasted for $24 \mathrm{~h}$ before sampling to allow evacuation of feed from the gastrointestinal tract for initial $(0 \mathrm{~h})$ sampling. At the each sampling time point (experiment 1: $0 \mathrm{~h}$ and $72 \mathrm{~h}$; experiment 2: $0 \mathrm{~h}, 12 \mathrm{~h}, 24 \mathrm{~h}, 48 \mathrm{~h}$, $72 \mathrm{~h}$ ), five fish per tank were randomly captured and anesthetized using $300 \mathrm{mg} / \mathrm{L}$ 2-phenoxyethanol $\left(\mathrm{C}_{8} \mathrm{H}_{10} \mathrm{O}_{2}\right.$, FW 138.2, Sigma-Aldrich, St. Louis, Mo, USA), and blood was collected from caudal vein using heparinized capillary tubes for determination of RBC count, and blood biochemical analyses (plasma glucose, GOT, GPT). Gills were sampled at $0 \mathrm{~h}$ and $72 \mathrm{~h}$ for histological examination. For the blood biochemical analyses, plasma was separated by centrifuging at $13,000 \mathrm{~g}$ for $15 \mathrm{~min}$ at $4^{\circ} \mathrm{C}$ and then the supernatant was stored at $-70^{\circ} \mathrm{C}$ until use. RBC count was carried out in microscopy with hemocytometers in that cells were suspended in a premade Hayem's solution. Plasma glucose (mg/dL), GOT (U/I), and GPT (U/I) were determined in duplicate using an automatic analyzer (FUJI DRI-CHEM 
NX500i, Fuji film Co., Japan), which was validated as a suitable method for fish plasma (Krome, 2014). The automatic analyzer was operated according to the manufacturer's protocol using selected testing slides (multi-layered slides, Fujifilm Co., Japan).

\section{Histological preparation and analysis}

Histological preparation and microscopic observation followed the method overall (Lee et al., 2012). Briefly, following anesthetization left side of whole gills were surgically removed and immediately fixed in Bouin's solution for histopathological examination. After being washed in tap water, the fixed tissues were dehydrated in a graded series of ethanol, cleared in xylene, infiltrated with paraffin using a tissue processor (TP1020, Leica, Germany) and embedded in paraffin blocks; serial sections ( $5 \mu \mathrm{m}$ thick) were prepared from each tissue using a microtome, placed on clean glass slides, dried in an incubation oven at $38^{\circ} \mathrm{C}$ for 48 hours, and stained with Mayer's hematoxylin (Sigma-Aldrich, St. Louis, MO, USA) and eosin (Eosin Y, Junsei Chemical Co., Tokyo, Japan). Histological changes were systemically examined under a microscope (BX-50, Olympus, Japan) (Teh et al., 2004).

\section{Data analysis}

Statistical analyses were conducted using SPSS Statistics 21 (IBM Corp., Chicago, IL). A two-way analysis of variance with interaction was used to test for significant differences among the different salinity treatments at different time points. Duncan's Multiple Range test was used for multiple comparisons between different treatment groups at each sampling time point. Statistical significance was tested at the 0.05 probability level, and all values are presented as mean \pm standard error of the mean, unless noted otherwise.

\section{RESULTS}

In experiment 1, E. akaara (mean TL: $8.1 \pm 0.2 \mathrm{~cm}$ ) exposed to 18 and 10 PSU for $72 \mathrm{~h}$ showed increased plasma glucose levels compared to the control (34 PSU), even though the increases were not significant (Fig. 1). The fish exposed to 18 and 10 PSU for $72 \mathrm{~h}$ showed significantly increased plasma GOT levels compared to the control $(n=5)$ but showed similar GOT values (Fig. 2). Regarding plasma GPT levels, salinity changes did not cause any significant

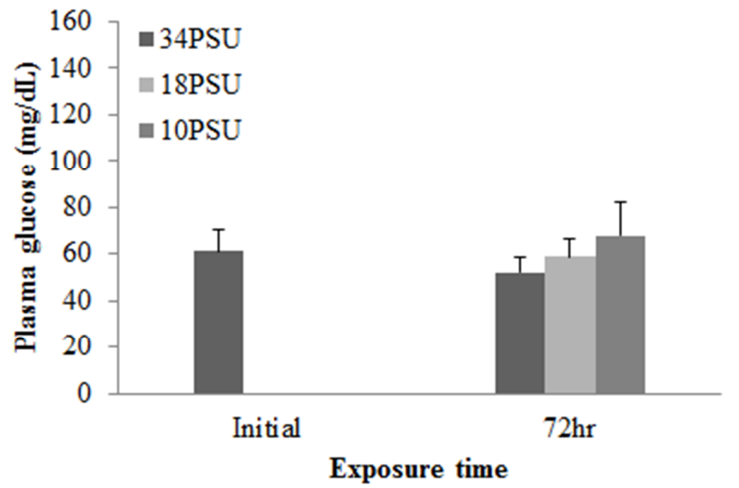

Fig. 1. Plasma glucose levels of Epinephelus akaara (150 DAH, mean body weight: $8.4 \pm 2.1 \mathrm{~g}$ ) exposed to 34, 18, 10 PSU for $72 \mathrm{~h}$. Vertica bar denotes a standard error of the mean.

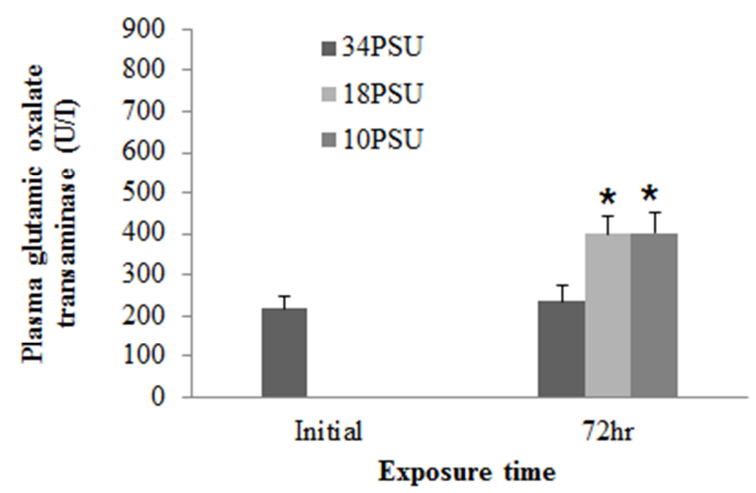

Fig. 2. Plasma glutamic oxalate transaminase levels of Epinephelus akaara (150 DAH, mean body weight: 8.4 $\pm 2.1 \mathrm{~g})$ exposed to $34,18,10 \mathrm{PSU}$ for $72 \mathrm{~h}$. Vertical bar denotes a standard error of the mean. Asterisk indicates a significant difference compared to the control (34 PSU) at $72 \mathrm{~h}(p<0.05)$ as determined by Duncan's multiple range test. 
changes in plasma GPT levels of different groups. However, fish exhibited higher mean GPT values at 18 and 10 PSU than at the control without statistical significance (Fig. 3).

In experiment 2, plasma glucose, GOT, and GPT levels of E. akaara (mean TL: $6.2 \pm 0.6 \mathrm{~cm}$ ) exposed to $26,18,10$ PSU for $12,24,48,72 \mathrm{~h}$ were determined. In regard to plasma glucose level, E. akaara exposed to 10 PSU showed significant increase from $12 \mathrm{~h}$ to $72 \mathrm{~h}(\mathrm{n}=5)$ (Fig. 4),

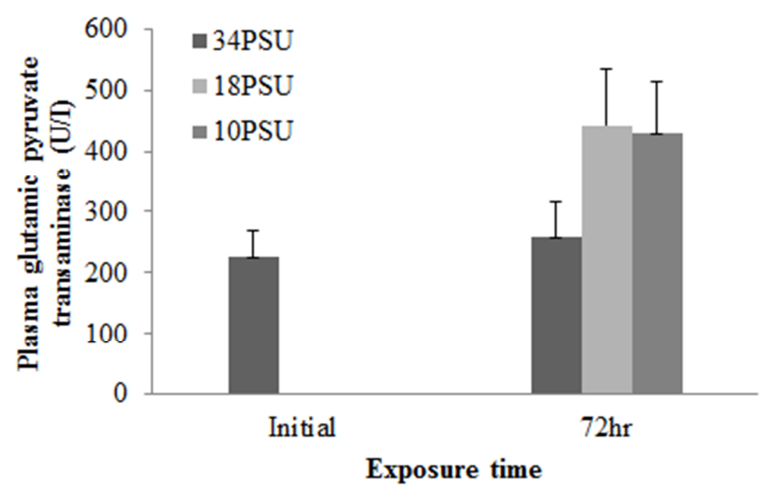

Fig. 3. Plasma glutamic pyruvate transaminase levels of Epinephelus akaara (150 DAH, mean body weight: 8.4 \pm 2.1g) exposed to 34, 18, 10 PSU for $72 \mathrm{~h}$. Vertical bar denotes a standard error of the mean.

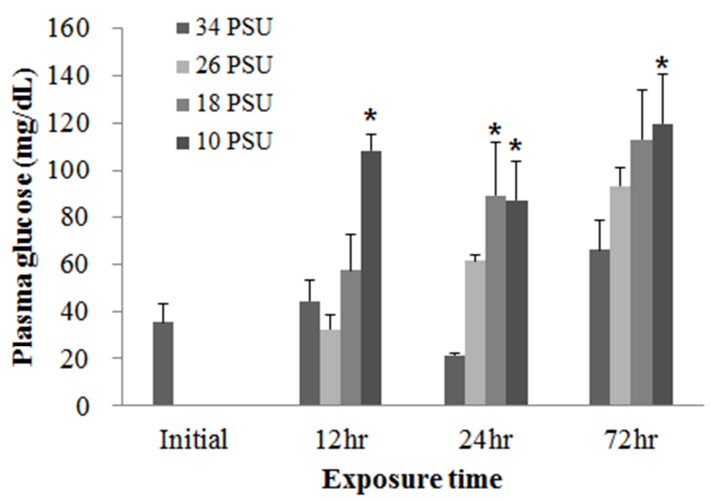

Fig. 4. Plasma glucose levels of Epinephelus akaara (120 DAH, average body weight: $3.3 \pm 0.6 \mathrm{~g})$ exposed to 34, 26, 18, 10 PSU for 12, 24, $72 \mathrm{~h}$. Vertical bar denotes a standard error of the mean. Asterisk indicates a significant difference compared to the value at $34 \mathrm{PSU}$ within each sample time point $(p<0.05)$ as determined by Duncan's multiple range test. whereas the increases in fish exposed to 18 PSU were not significant. Glucose levels at $48 \mathrm{~h}$ were not presented due to limited blood volume.

With regard to plasma GOT levels, E. akaara exposed to 26, 18, $10 \mathrm{PSU}$ at $12 \mathrm{~h}$ post-drop showed a dose-dependent increases compared to the control, but only fish exposed to 10 PSU showed a significant increase compared to the control. E. akaara exposed to 18 or 10 PSU showed significantly increased GOT levels at $48 \mathrm{~h}$ post-drop. At $72 \mathrm{~h}$ post-drop, only fish exposed to 10 PSU exhibited a significant increase compared to the control. Data on $24 \mathrm{~h}$ were not presented due to limited blood volumes (Fig. 5).

In regards to $\mathrm{RBC}$ count, after E. akaara exposed to 10 PSU showed a significant decrease at $12 \mathrm{~h}$ post-drop, fish exposed to 18 and 10 PSU exhibited significant increases from 24 to $72 \mathrm{~h}$ post-drop, compared to the control (Fig. 6).

In regard to histological changes of the gills, slight proliferation of epithelium (hyperplasia) and epithelium lifting in the secondary lamellae were observed in fish exposed to 18 and 10 PSU (Figs. 7. D and F). A single layer of epithelium

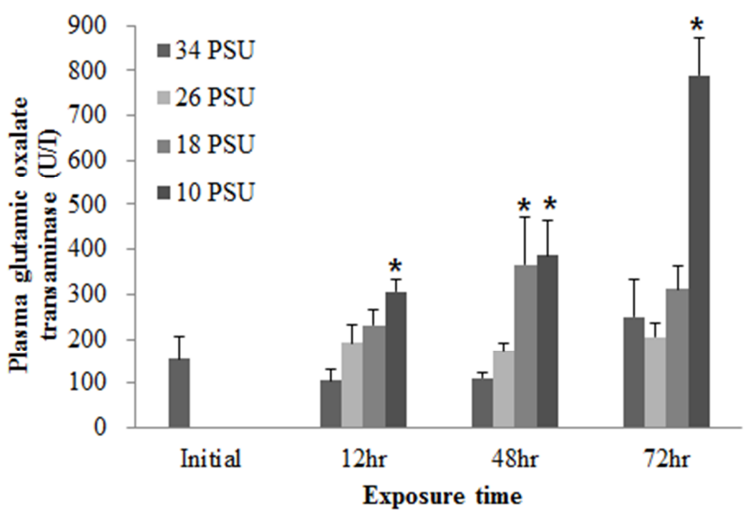

Fig. 5. Plasma glutamic oxalate transaminase levels of Epinephelus akaara (120 DAH, average body weight: $3.3 \pm 0.6 \mathrm{~g}$ ) exposed to $34,26,18,10 \mathrm{PSU}$ for $12,48,72 \mathrm{~h}$. Vertical bar denotes a standard error of mean. Asterisk indicates a significant difference compared to the value at 34 PSU within each sample time point $(p<0.05)$ as determined by Duncan's multiple range test. 


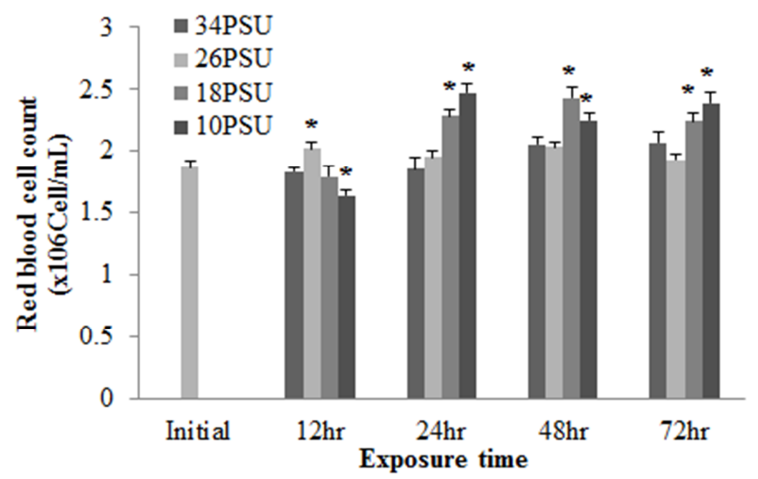

Fig. 6. Red blood cell count of Epinephelus akaara (120 DAH, average body weight: $3.3 \pm 0.6 \mathrm{~g}$ ) exposed to $34,26,18,10$ PSU for initial, 12, 24, 48, $72 \mathrm{~h}$. Vertical bar denotes a standard error of the mean. Asterisk indicates a significant difference compared to the value at 34 PSU within each sample time point $(p<0.05)$ as determined by Duncan's multiple range test.

in the secondary lamellae for effective gas exchanges, which is supported by pillar cells, was disintegrated in some parts of fish gills exposed to 18 and 10 PSU (Figs. 7. D and F).

\section{DISCUSSION}

The two size groups of juvenile E. akaara (mean TL $8.1 \pm 0.22 \mathrm{~cm}$ and $6.2 \pm 0.6 \mathrm{~cm}$, respectively) exposed to 18 or 10 PSU for $72 \mathrm{~h}$ in the current study are still in the primary adjustment phase (Laiz-Carrion et al., 2005; SangiaoAlvarellos et al., 2005). However, E. akaara exposed to 26 PSU in experiment 2 do not seem to be affected by low salinity challenge. This conclusion is supported by the following findings. First, the fish exposed to 18 and 10 PSU exhibited the significantly increased plasma glucose, GOT, and RBC counts compared to the control (34 PSU) at $72 \mathrm{~h}$ post-drop (Figs. 1-6). Second, the blood stress parameters, especially plasma glucose and GOT, do not seem to reach a plateau at $72 \mathrm{~h}$ post-drop in experiment 2 (Figs. 4 and 5). Lastly, histopathological changes in the gills of fish exposed to 18 and 10 PSU were mild but distinct (Fig. 7). However, further studies with longer exposure period (e.g. more 14 days) and additional parameters (e.g. gill $\mathrm{Na}^{+} \mathrm{K}^{+}$ATPase activity, plasma osmolality) is needed for deeper

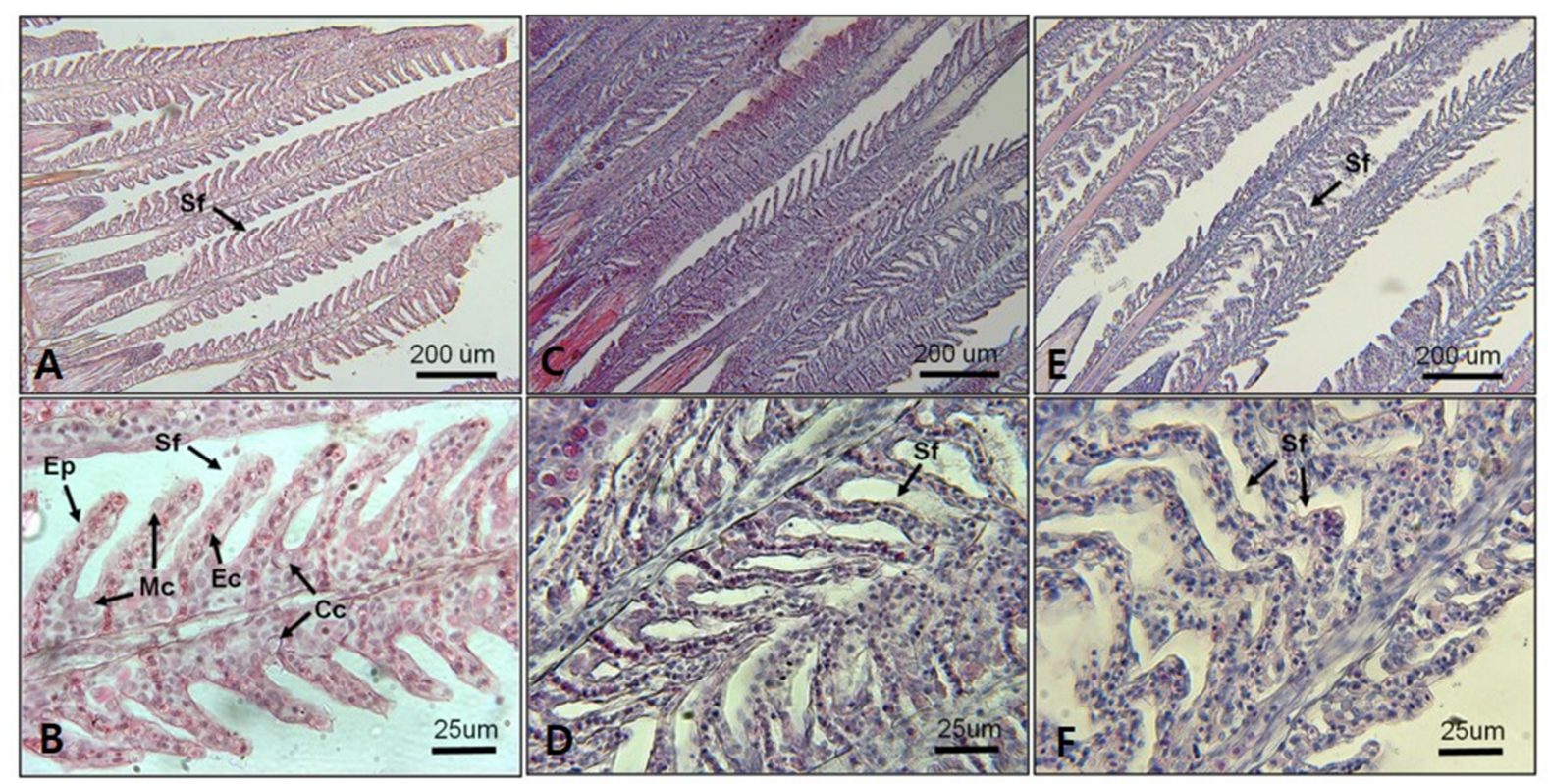

Fig. 7. Histological alteration in the gills of Epinephelus akaara (150 DAH, mean body weight: 8.4 $\pm 2.1 \mathrm{~g})$ abruptly exposed to 34, 18, 10 PSU for 72 h (experiment 1). A, B: 34 PSU; C, D: 18 PSU; E, F: 10 PSU; Cc, chloride cell; Ec, erythrocyte; Ep, epithelial cell; Mc, mucous cell; Sf, secondary 
under-standing of osmoregulatory responses of E. akaara to low salinity challenges.

In response to salinity changes, fish undergo two osmoregulatory phases: first, an primary adjustment phase with alternations in osmoregulatory variables (including plasma osmolality and electrolyte concentrations), and then a secondary chronic regulatory phase, where osmotic parameters reach a new homeostasis (Laiz-Carrion et al., 2005; SangiaoAlvarellos et al., 2005; Arjona et al., 2007). The ranges of primary adjustment phase in fish are species-dependent. In our study, RBC counts started to show changes at $12 \mathrm{~h}$ post-drop. Later, RBC counts in fish exposed to 18 and 10 PSU seem to reach a plateau from $24 \mathrm{~h}$ post-drop (Fig. 6). However, other blood parameters (plasma glucose and GOT) in experiment 2 do not seem to reach a plateau yet at $72 \mathrm{~h}$ post-drop (Figs. 4 and 5). Modifications in osmoregulatory parameters such as electrolyte concentrations of partially euryhaline species are often detected within 2-3 days after transfer (Laiz-Carrion et al., 2005; SangiaoAlvarellos et al., 2005). In a salinity-challenge study on Senegalese sole (Solea senegalensis), the adjustment period in fish involved approximately 7 days and then the chronic regulatory phase at day 14 or day 17 (Arjona et al., 2007). In another study on Sparus auratus, an adjustment period lasted for the first three days of acclimation in hyper- and hypo-osmotic challenges (Sangiao-Alvarellos et al., 2005).

The increased plasma glucose level is an indicator of the secondary stress response in fish (Moyle \& Cech, 2004). In experiment 1, E. akaara exposed to 34,18 , or $10 \mathrm{PSU}$ did not show significant difference in plasma glucose levels between the different treatments, even though mean values were higher with lower salinity (Fig. 1). The no significant difference in glucose level between the treatments seem to be associated with individual variations and/or limited sample size $(n=5)$. In experiment 2 , our result that the significant increase in plasma glucose level of $E$. akaara exposed to 18 and 10 PSU compared to the control generally agree with a previous study on osmoregulatory response of Senegalese sole by (Arjona et al., 2007). Arjona et al. (2007) reported the significantly increased plasma glucose levels in the sole at a salinity drop to $5 \%$, but not to $15 \%$, from $38 \%$, in which the glucose levels were kept increased until 5-6 days post-drop compared to the control (38\%o). Based only on glucose levels, E. akaara may be more stenohaline than Senegalese sole because of increased glucose levels in experiment 2 at 18 PSU. The increased plasma glucose levels are stimulated by catecholamines and/or cortisol (Mommsen et al., 1999). Plasma cortisol level is a primary stress response to various stressors in teleost (Mommsen et al., 1999; Moyle \& Cech, 2004). Environmental salinity has been accepted as a stress that induces a primary stress response and cortisol release into blood stream (Moyle \& Cech, 2004). It is speculated that the elevated plasma glucose levels observed in the current study were likely to be mediated by the plasma cortisol influx into the blood with uncertainty on role of plasma catecholamines in this context.

GOT and GPT are enzymes found in the liver, heart, skeletal muscle (Bhattacharya et al., 2008). These two enzymes in blood serum have been considered as indicators of hepatic dysfunction and damage (Wang et al., 2005; Ming et al., 2012). In healthy conditions, GPT and GOT are dominant in hepatocytes and cardiomyocytes, respectively. They are vital components in protein metabolism (Harper, 1978), and play important roles in the utilization of amino acids for oxidation and/or for gluconeogenesis (Rodwell, 1988). When liver and myocardiocytes are damaged or their permeability increased, GOT and GPT are released into the blood, leading to elevated blood transaminase activity (Wang et al., 2005; Gholami-Seyedkolaei et al., 2013). Thus, plasma GOT and GPT can be used to detect tissue damage in fish. Ming et al. (2012) reported that when freshwater bream (Megalovrama amblycephala) were under heat stress at $34^{\circ} \mathrm{C}$, GOT and GPT levels were 
significantly elevated. In the current study, plasma GOT levels in E. akaara exposed to 18 or 10 PSU was significantly increased compared to the control during the $72 \mathrm{~h}$ challenge. Especially, fish exposed to 10 PSU showed increases in a time-dependent manner (Fig. 5), which suggests that E. akaara exposed to 10 PSU may have compromised hepatocyte and/or myocardiocyte function.

Mild epithelial hyperplasia and lifting observed in the secondary lamellae of E. akaara exposed to 18 and 10 PSU have been previously reported as toxin-induced stress responses in other fish species (Deng et al., 2008; Lee et al., 2012). The observed hyperplasia and lifting of the epithelium in the secondary lamellae could have interfered with the efficient gas exchange in the gills (Lee et al., 2012). However, it is speculated that, because the lesions were not severe, the fish may have compensated for the reduced efficiency by increasing the RBC volume, gill ventilation rate, cardiac output, or lamellar recruitment to meet the possibly increased demand in gas exchanges induced by salinity changes in the current study (Moyle \& Cech, 2004). Also, it is possibly speculated that the increased RBC at 18 and 10 PSU (Fig. 6) could be one of the aforementioned respiratory compensation mechanisms for gill morphological modification observed in the current study (Fig. 7). At this point, we are not sure whether the histological alterations observed in the two salinities treatment at $72 \mathrm{~h}$ post-drop are reversal or not.

It is suggested that E. akaara exposed to sudden salinity drops to 18 or 10 PSU still undergoes the primary adjustment phase ("alarming stage") before the fish reach a new homeostasis ("resistant stage"), based on our current results on the elevated levels of plasma stress parameters of overall increasing trends and mild but distinct alterations in gill histology at $72 \mathrm{~h}$ post-drop. On the other hand, fish exposed to salinity drop from 34 to 26 PSU seems to mount stress from salinity change or might already pass the adjustment phase and reach a new homeostasis. Therefore, the no observed adverse effect levels for $72 \mathrm{~h}$ acute salinity challenge was 26 PSU in our study, and acute salinity drop to 18 PSU and below can possibly cause acute adverse effect, which could make the fish in this size vulnerable to possible additional stresses such as a temperature fluctuation. Additional studies with longer experimental duration promise establishing more definitive conclusion on salinity responses of this species.

\section{ACKNOWLEDGEMENT}

This research was supported by the Korean Ministry of Agriculture, Food and Rural Affairs (MAFRA), the Korean Ministry of Oceans and Fisheries (MOF), the Korean Rural Development Administration (RDA), and Korea Forest Service (KFS) under grant (number: 213004-04-04-SB620). We thank Professor Young Don Lee for generously providing the juvenile grouper for this study from the Marine Science Research Institute, Jeju National University. We also appreciate the provision of the juvenile grouper from Chung-sol Fish Farm, Muangoon, Korea.

\section{AUTHORS' CONTRIBUTIONS}

Jang-Won Lee has analyzed and interpreted the results and written the manuscript. Hyung Bae Kim has contributed to designing experiments and revising manuscript. Hea Ja Baek has made major contribution to collection of data and experimental design and been involved in drafting and critically revising the manuscript.

\section{REFERENCES}

Akatsu S, Al-Abdul-Elah KM, Teng SK (1983) Effects of salinity and water temperature on the survival and growth of brown-spotted grouper larvae (Epinephelus tauvina, Serranidae). J World Aquacult Soc 14:624-635. 
Arjona FJ, Vargas-Chacoff L, Ruiz-Jarabo I, Goncalves O, Pascoa I, Martin Del Rio MP, Mancera JM (2009) Tertiary stress responses in Senegalese sole (Solea senegalensis Kaup, 1858) to osmotic challenge: Implications for osmoregulation, energy metabolism and growth. Aquaculture 287: 419-426.

Arjona FJ, Vargas-Chacoff L, Ruiz-Jarabo I, Martin Del Rio MP, Mancera JM (2007) Osmoregulatory response of Senegalese sole (Solea senegalensis) to changes in environmental salinity. Comp Biochem Physiol Part A 148:413-421.

Asztalos B, Nemcsok J, Benedeczky I, Gabriel R, Szabo A, Refaie OJ (1990) The effects of pesticides on some biochemical parameters of common carp (Cyprinus carpio). Arch Environ Contam Toxicol 19:275-282.

Bhattacharya H, Xiao Q, Lun L (2008) Toxicity study of nonylphenol on rosy barb (Puntius conchonious): A biochemical and histopathological evaluation. Tissue Cell 40:243-249.

Cho HC, Kim JE, Kim HB, Baek HJ (2015) Effects of water temperature change on the hematological responses and plasma cortisol levels in growing of red spotted grouper, Epinephelus akaara. Dev Reprod 19:19-24.

Cornish A (2003) Epinephelus akaara. The IUCN red list of threatened species. version 2015. 2; DOI: http://dx. doi.org/10.2305/IUCN.UK.2003.RLTS.T43974A1084 6282.en. accessed 28 October 2015.

Datta S, Saha DR, Ghosh D, Majumdar T, Bhattacharya S, Mazumder S (2007) Sub-lethal concentration of arsenic interferes with the proliferation of hepatocytes and induces in vivo apoptosis in Clarias batrachus L. Comp Biochem Physiol C Toxicol Pharmacol 145:33949.

Deng DF, Teh FC, Teh SJ (2008) Effect of dietary methylmercury and selenomethionine on Sacramento splittail larvae. Sci Total Environ 407:197-203.
Gholami-Seyedkolaei SJ, Mirvaghefi A, Farahmand H, Kosari AA, Gholami-Seyedkolaei SJ, Gholami-Seyedkolaei SJ (2013) Optimization of recovery patterns in common carp exposed to roundup using resonse surface methodology: Evaluation of neurotoxicity and genotoxicity effects and biochemical parameters. Ecotox Environ Saf 98: 152-161.

Harper HA, Rodwell VW, Mayer PA (1978) Review of Physiological Chemistry, $17^{\text {th }}$ ed. Lange Medical Publication, California.

Jensen FB, Lecklin T, Busk M, Bury NR, Wilson RW, Wood CM, Grosell M (2002) Physiological impact of salinity increase at organism and red blood cell levels in the European flounder (Platichthys flesus). J Exp Mar Biol Ecol 247:159-174.

Kindle KR, Whitmore DH (1986) Biochemical indicators of thermal stress in Tilapia aurea (Steindachner). J Fish Biol 29:243-255.

Krome CA (2014) Studies on the suitability of Jatropha curcas kernel meal as an alternative protein source in diets for carp (Cyprinus carpio) and tilapia (Oreochromis niloticus). Thesis. University of Stirling, Stirling, UK.

Laiz-Carrion R, Guerreiro PM, Fuentes J, Canario AVM, Martin del Rio MP, Mancera JM (2005) Branchial osmoregulatory response to salinity in the gilthead sea bream, Sparus auratus. J Exp Zool 303:563-576.

Laiz-Carrion R, Sangiao-Alvarellos S, Guzman JM, Martin del Rio MP, Minguez J, Soengas JL, Mancera JM (2002) Energy metabolism in fish tissues related to osmoregulation and cortisol action. Fish Physiol Biochem 27:179-188.

Lee JW, Kim JW, De Riu N, Moniello G, Hung SSO (2012) Histopathological alterations of juvenile green (Acipenser medirostris) and white sturgeon (Acipenser transmontanus) exposed to graded levels of dietary methylmercury. Aquat Toxicol 109:90-99. 
Lü W, Li W, Ke C, Wang H (2015) Reproductive success under the joint influences of temperature and salinity in noble scallop, Chlamys nobilis (Reeve). Aquacult Res $1-11$.

Ming J, Xie J, Wu P, Ge X, Liu W, Ye J (2012) Effects of emodin and vitamin $\mathrm{C}$ on growth performance, biochemical parameters and two HSP70s mRNA expression of Wuchang bream (Megalobrama amblycephala Yih) under high temperature stress. Fish Shellfish Immun 32:651-661.

Mommsen TP, Vijayan MM, Moon TW (1999) Cortisol in teleost: Dynamics, mechanisms of action, and metabolic regulation. Rev Fish Biol Fish 9:211-268.

Morris AV, Roberts C, Hawkins J (2000) The threatened status of groupers (Epinephelinae). Biodivers Conserv 9:919-942.

Moyle PB, Cech JJ (2004) An Introduction to Ichthyology. Fifth ed. Prentice Hall, Upper Saddle River, NJ, USA.

Park, JY, Cho, JK, Son, MH, Kim, KM, Han, KH, Park, JM (2016) Artificial spawning behavior and development of eggs, larvae and juveniles of the red spotted grouper, Epinephelus akaara in Korea. Dev Reprod 20:31-40.

Randall JE (1987) A preliminary synopsis of the groupers (Perciformes: Serranidae: Epinephelinae) of the IndoPacific region. In: Polovina JJ and Ralston S (ed.), Tropical Snappers and Groupers: Biology and Fisheries Management. Westview Press, Boulder, Colorado, USA, pp 89-189.
Rodwell VW (1988) Metabolism of proteins and amino acids. In: Rodwell VW (ed.), Review of Biochemistry. Lange Medical Publications, California, USA, pp 265-319.

Sangiao-Alvarellos S, Arjona FJ, Martin del Rio MP, Miguez JM, Mancera JM, Soengas JL (2005) Time course of osmoregulatory and metabolic changes during osmotic acclimation in Sparus auratus. J Exp Biol 208:4291-4304.

Shahkar E, Kim D-J, Mohseni M, Yun H, Bai SC (2015) Effects of salinity changes on hematological responses in juvenile ship sturgeon Acipenser nudiventris. Fish Aquat Sci 18:45-50.

Teh SJ, Adams SM, Hinton DE (1997) Histopathologic biomarkers in feral freshwater fish populations exposed to different types of contaminant stress. Aquat Toxicol 37:51-70.

Teh SJ, Deng X, Deng DF, Teh FC, Hung SSO (2004) Chronic effects of dietary selenium on juvenile Sacramento splittail (Pogonichthys macrolepidotus). Environ Sci Technol 38:6085-6093.

Vargas-Chacoff L, Arjona FJ, Polakof S, Martin del Rio MP, Soengas JL, Mancera JM (2009) Interactive effects of environmental salinity and temperature on metabolic responses of gilthead sea bream Sparus aurata. Comp Biochem Physiol Part A 154:417-424.

Wang YL, Xiong K, Yang J, Wu Z, Sheng XM, Tang HF (2005) Effect of beta-cypermethrin on GPT and GOT activities of crucian serum. Agr Sci Technol 6:20-23. 